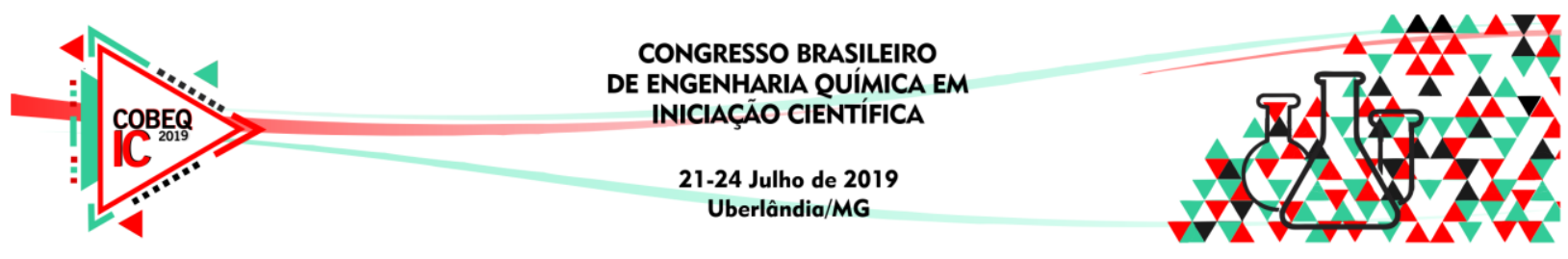

\title{
ESTUDO DE DISSOLUÇÃO ÁCIDA DE SILTITOS VERDES
}

\author{
G. R. S. SOUZA, R. S. SCHIMICOSCKI, K. D. OLIVEIRA e C. N. ÁVILA NETO \\ Universidade Federal de Uberlândia, Faculdade de Engenharia Química \\ E-mail para contato: gabrielrss@ufu.br
}

\begin{abstract}
RESUMO - A viabilidade da utilização de rochas silicatadas como fonte de potássio têm sido uma peça chave para o agronegócio no Brasil. Um minério silicatado rico em íons $\mathrm{K}^{+}$, denominado "Verdete", foi tratado hidrotermicamente na presença de ácido sulfúrico, variando a metodologia e tempo de reação. O objetivo foi estudar a cinética da lixiviação visando a extração dos íons $\mathrm{K}^{+}$ presentes no verdete através da reação com ácido sulfúrico. O produto das reações foi analisado por fotometria de chama, microscopia eletrônica de varredura e difratograma de raio $\mathrm{X}$, obtendo-se a fração de potássio extraída do minério. Os resultados demonstraram que, a maior razão líquido-sólido proporcionou uma maior extração do potássio, em um maior tempo. E que na reação de menor RLS e diferente método de extração, após 5 min de reação, atingiu-se um máximo de extração de potássio (10\%), e que a fração solúvel é composta de sulfatos variados, como por exemplo, $\mathrm{K}_{2} \mathrm{Fe}_{5} \mathrm{AlFe}_{3}\left(\mathrm{SO}_{4}\right)_{12} \mathrm{H}_{2} \mathrm{O}$.
\end{abstract}

\section{INTRODUÇÃO}

O Brasil apesar de ser um dos países que mais demandam potássio no mundo, a produção doméstica de potassa, na forma exclusiva de $\mathrm{KCl}$, produzida unicamente no complexo de Taquari-Vassouras (Se), representa somente cerca de 10\% do consumo interno aparente.

Dentre as rochas silicatadas o "Verdete", encontrado nos municípios de Matutina, Cedro e Cedro do Abaeté, no estado de Minas Gerais possui o teor de $\mathrm{K}_{2} \mathrm{O}$ variando de 9 a $11 \%$, e é constituído majoritariamente por uma mistura de glauconita, muscovita e feldspato potássico. De acordo com a U.S Geological Survey (2018), todavia, a utilização de fontes de baixo teor de potássio como fertilizante só seria viável economicamente se os locais de cultivo estiverem localizados relativamente próximos da mina. É por isto que o tratamento prévio e o enriquecimento do "Verdete" com produtos solúveis é uma peça chave para o agronegócio no Brasil.

A maneira mais simples de aumentar a solubilidade de rochas potássicas é a inserção de uma fonte externa de energia, num processo capaz de romper ou alterar a estrutura cristalina dos minerais portadores de nutrientes e aumentar sua solubilidade (LEITE, 1985).

Tratamentos químicos como a acidificação ou a alcalinização são caracterizados por quebrarem as ligações que dão estrutura ao mineral, objetivando solubilizar algum elemento da rocha. Considerando os tratamentos existentes e os estudos já realizados até então, concluise que geralmente, a eficácia agronômica das rochas possui relação direta com vários sendo 


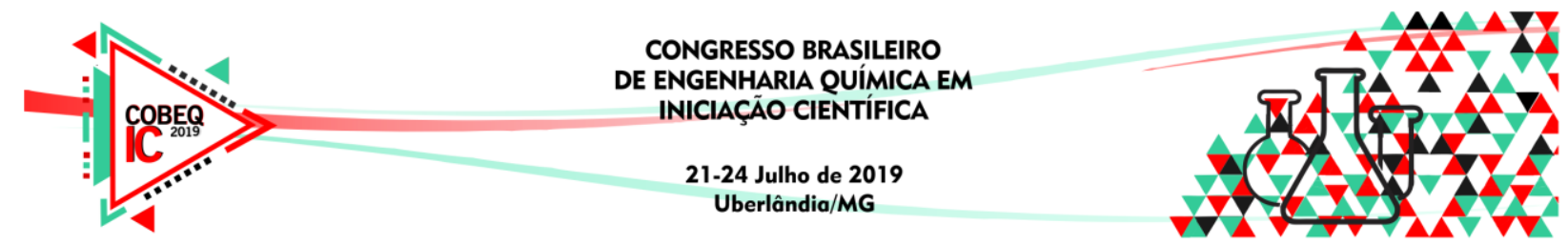

eles: a sua origem e composição; das características do solo; do tratamento químico ou físico empregado e das culturas utilizadas; do tempo de exposição: e ainda, características do tratamento usado.

Este trabalho tem como objetivo realizar um tratamento químico do Verdete com ácido sulfúrico, caracterizar os produtos da reação e estudar os efeitos das variáveis do processo objetivando otimizar a reação, e, finalmente, entender o mecanismo específico de lixiviação de potássio.

\section{METODOLOGIA}

O desenvolvimento deste trabalho aconteceu no Laboratório de Cinética de Reações Sólido-Fluido da Universidade Federal de Uberlândia - UFU.

Realizou-se uma série de reações, utilizando um conjunto de cinco reatores do tipo autoclave, revestidos com teflon internamente e com corpo de aço-inox, que pode ser visto na Figura 1. A alimentação foi constituída por "Verdete" com diâmetro menor que 149 micrômetros, ácido sulfúrico e água. As reações foram realizadas a $453 \mathrm{~K}$, com concentração de $\mathrm{H}_{2} \mathrm{SO}_{4}$ de $1 \mathrm{~mol} \mathrm{~L}^{-1}$ e diferentes razões líquido-sólido (L/S), como mostra a Tabela 1.

Figura 1 - (A) Reator tipo autoclave e (B) parte interna do reator.
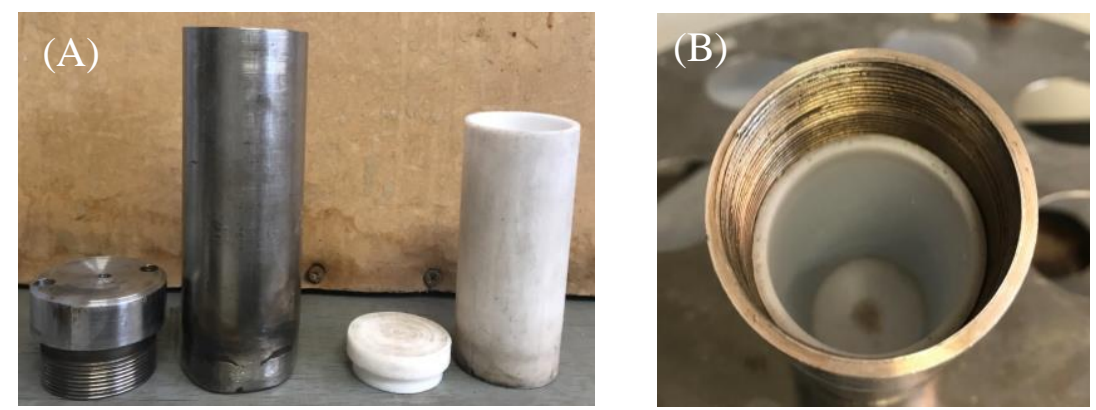

Tabela 1 - Massa e volume de reagentes alimentados ao reator.

\begin{tabular}{|c|c|c|c|}
\hline Método & Verdete (g) & $\mathrm{H}_{2} \mathrm{SO}_{4} 1 \mathrm{~mol} \mathrm{~L}^{-1}(\mathrm{~mL})$ & Razão L/S (mL g $\left.{ }^{-1}\right)$ \\
\hline (1) & 11,15 & 23,6 & 2,11 \\
\hline (2) & 2,36 & 23,6 & 10 \\
\hline
\end{tabular}

Nas análises de fotometria de chama, o manejo dos produtos hidrotermais foi realizado de duas formas distintas. No Método 1, os produtos foram mantidos em estufa por um dia e, após secagem, foram extraídos (1 g de produto seco) com $100 \mathrm{~mL}$ de uma solução de ácido cítrico $2 \%\left(20 \mathrm{~g} \mathrm{~L}^{-1}\right)$. No Método 2, os produtos hidrotermais passaram por um processo de maceração para, posteriormente, serem extraídos com $100 \mathrm{~mL}$ de água. Para determinar o teor de potássio solúvel, foi utilizada a técnica de fotometria de chama com um equipamento Analyzer 910MS. 


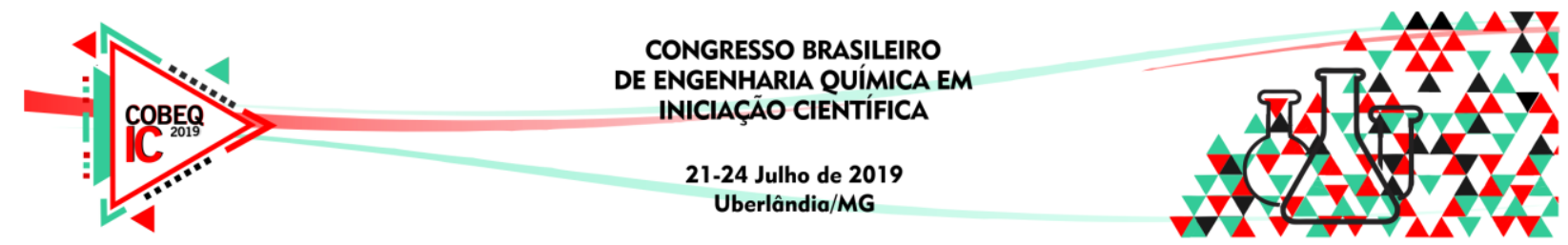

Para as análises de difração de raios X (DRX), utilizou-se um equipamento Shimadzu XRD-6000, empregando $\mathrm{Cu} \mathrm{K} \alpha(\lambda=1.54056 \AA)$ com filtro de $\mathrm{Ni}$, voltagem de $40 \mathrm{kV}$ e corrente de $30 \mathrm{~mA}$. $\mathrm{O}$ ângulo $2 \theta$ usado para escanear foi de $5^{\circ}$ até $55^{\circ} \mathrm{com}$ a taxa de $2^{\circ} \mathrm{min}^{-1}$. Já as análises de microscopia eletrônica de varredura (MEV), foram obtidas com o equipamento EVO® MA 10 a $20 \mathrm{kV}$. As amostras foram dispersas em porta-amostras de alumínio e cobertas por uma fina camada de ouro (metalização). E as análises de espectroscopia de energia dispersiva (EDS) foram obtidas em um equipamento Oxford instrument model 51-ADD0048.

\section{RESULTADOS E DISCUSSÃO}

Realizaram-se as reações em diferentes tempos, e os resultados da caracterização dos produtos das reações são apresentados a seguir. Para iniciar a discussão, tem-se o resultado a partir do fotômetro, que fornece o teor de potássio solúvel de cada uma das amostras.

Partindo desses dados fez-se um gráfico da média do $\left(\mathrm{K}_{\text {extraído }} / \mathrm{K}_{\text {total }}\right)$ versus o tempo com o seu desvio padrão. Tem-se a seguir a Figura 2 que traz os dados citados anteriormente.

Figura 2 - Gráfico da média dos resultados e seu desvio padrão (A) razão $\mathrm{L} / \mathrm{S}=2,11$ e (B) razão $\mathrm{L} / \mathrm{S}=10,0$.

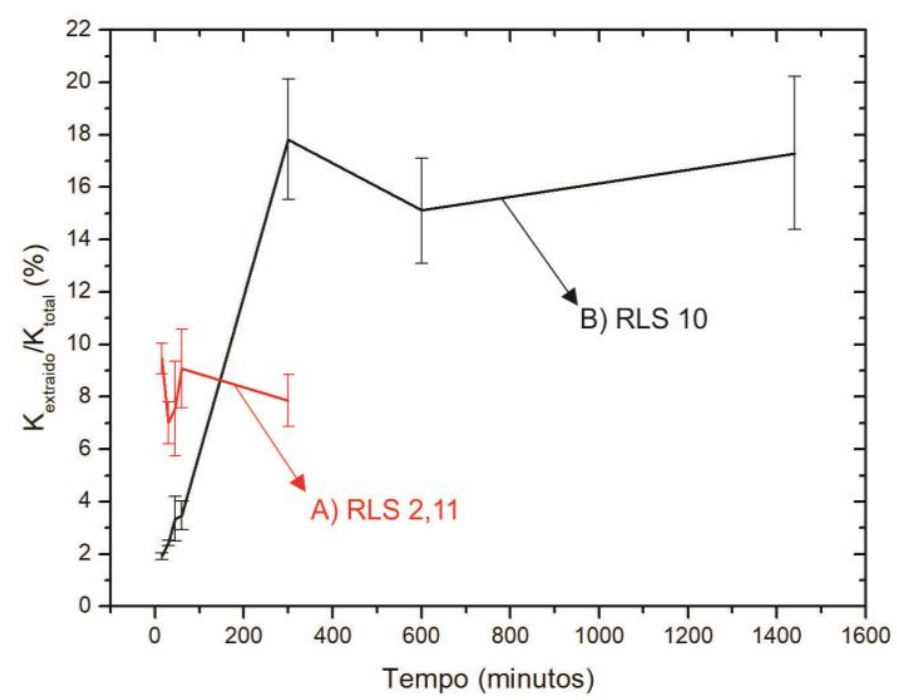

Observando os resultados da Figura 2 (razão L/S = 2,11) nota-se que foi extraído quase $10 \%$ do potássio total presente no verdete e que esse pico de extração ocorreu com um baixo tempo de reação. Nota-se também que existe um pico ente 5 e 15 minutos, seguido por uma queda na solubilização entre os tempos de 30 e 45 minutos e aparece novamente um novo pico em uma hora de reação. Para $\mathrm{R} / \mathrm{L}=10$, foi extraído mais de $18 \%$ do potássio total presente, e diferentemente da RLS anterior, ouve um crescimento da extração com o passar do tempo, com o pico em 300 minutos.

Para caracterizar os produtos obtidos no primeiro método (extração com ácido cítrico $2 \%$ ) nos diferentes tempos de reação, foram realizadas análises de DRX e para efeito de comparação da evolução da reação com o passar do tempo na figura 3 plotou-se as linhas de 


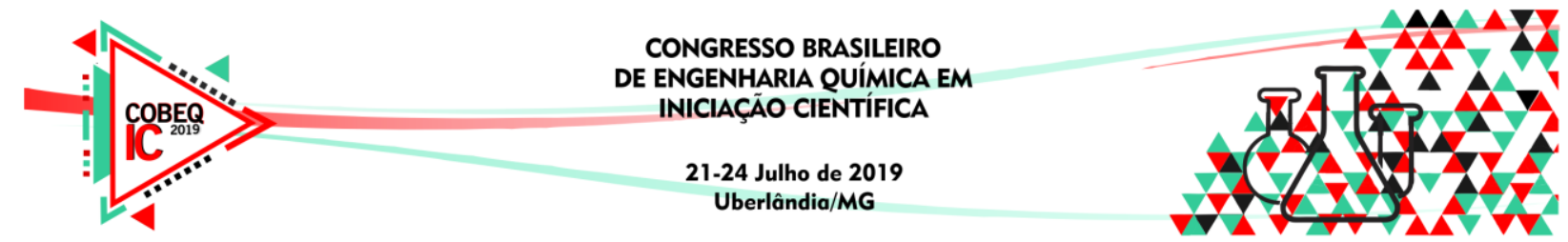

difração do verdete in natura, dos produtos dos tempos 15 e 60 minutos que obtiveram os picos de solubilização e do produto da reação de 30 minutos que obteve o mínimo de solubilização do potássio.

Figura 3 - (A) Gráfico comparativo do DRX com o passar do tempo de reação. (B) DRX da amostra da reação com duração de 15 minutos.

(A)

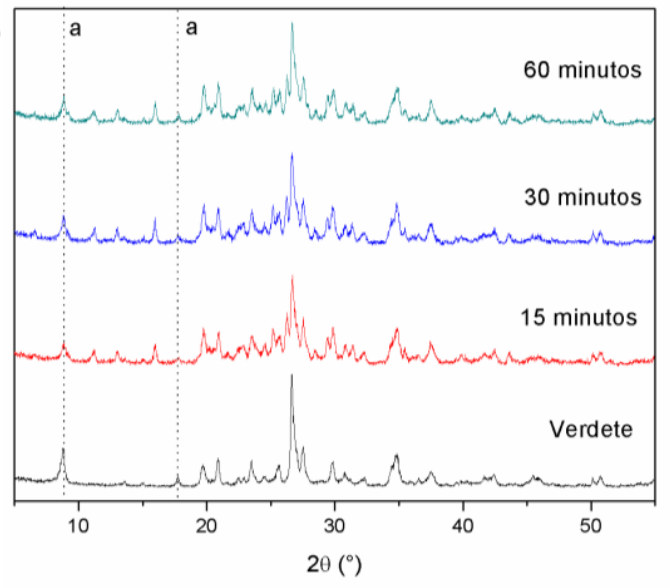

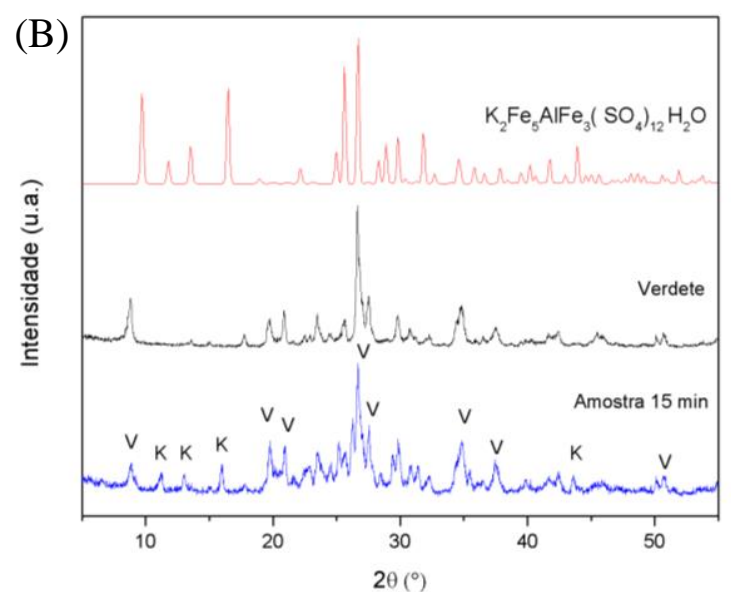

Ao comparar as linhas de difração de cada produto, nota-se que mesmo a porcentagem de solubilização não sendo a mesma, essas linhas são bastante semelhantes indicando que os minerais relacionados aos planos cristalográficos foram consumidos ou formados desde os primeiros 15 minutos de reação. Os picos identificados por $a$, na Figura 3-A, são correspondentes a muscovita que provavelmente foi consumida, onde em 15 minutos (amostra com maior solubilidade) esses picos mostraram uma menor intensidade.

Objetivando identificar os componentes dos produtos formados, fez-se a análise de compatibilidade das linhas de difração da amostra obtida com 15 minutos de reação com a base de dados ICSD (Inorganic Crystal Structure Database). Escolheu-se a amostra obtida da reação com duração de 15 minutos, já que foi o produto que mostrou melhores resultados em relação a solubilização do potássio e também devido as semelhanças dos difratogramas de raios $\mathrm{X}$ das amostras, ele pode representar o produto formado nos 3 tempos analisados. Os componentes identificados nessa amostra estão apresentados na Figura 3-B.

A partir das linhas dos difratogramas da Figura 3 (B), sugere-se a formação de um sulfato, o $\mathrm{K}_{2} \mathrm{Fe}_{5} \mathrm{AlFe}_{3}\left(\mathrm{SO}_{4}\right)_{12} \mathrm{H}_{2} \mathrm{O}$ (ICSD 9254). Aparecendo na Figura 3-B, nos picos de difração indicados pela letra $k$. Outras linhas de difração identificadas no produto obtido possivelmente são provenientes do verdete in natura não reagido, na Figura 3 (B) os picos estão identificados pela letra $v$.

A composição elementar do produto obtido após 15 minutos de reação foi estimada aplicando-se análise EDS em quatro pontos escolhidos do MEV desse material. Os pontos escolhidos e os resultados obtidos estão na Figura 4 e na Tabela 3. 


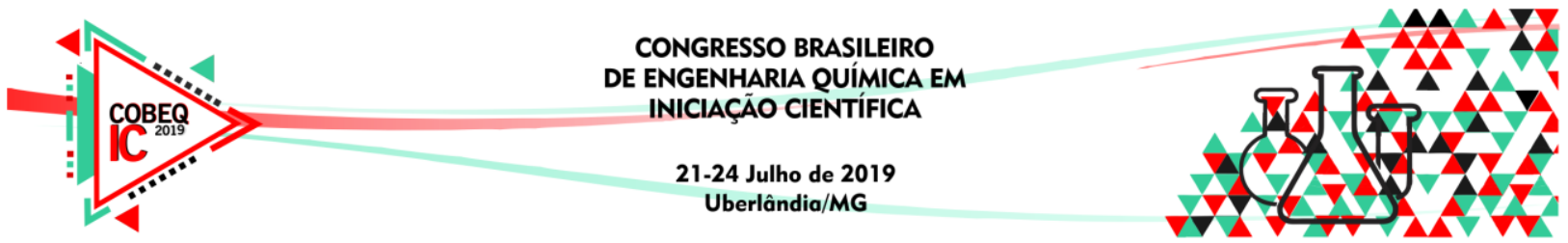

Figura 4 - (A e B) MEV e EDS do produto da reação de 15 minutos entre o verdete e o ácido sulfúrico (1 mol/L).
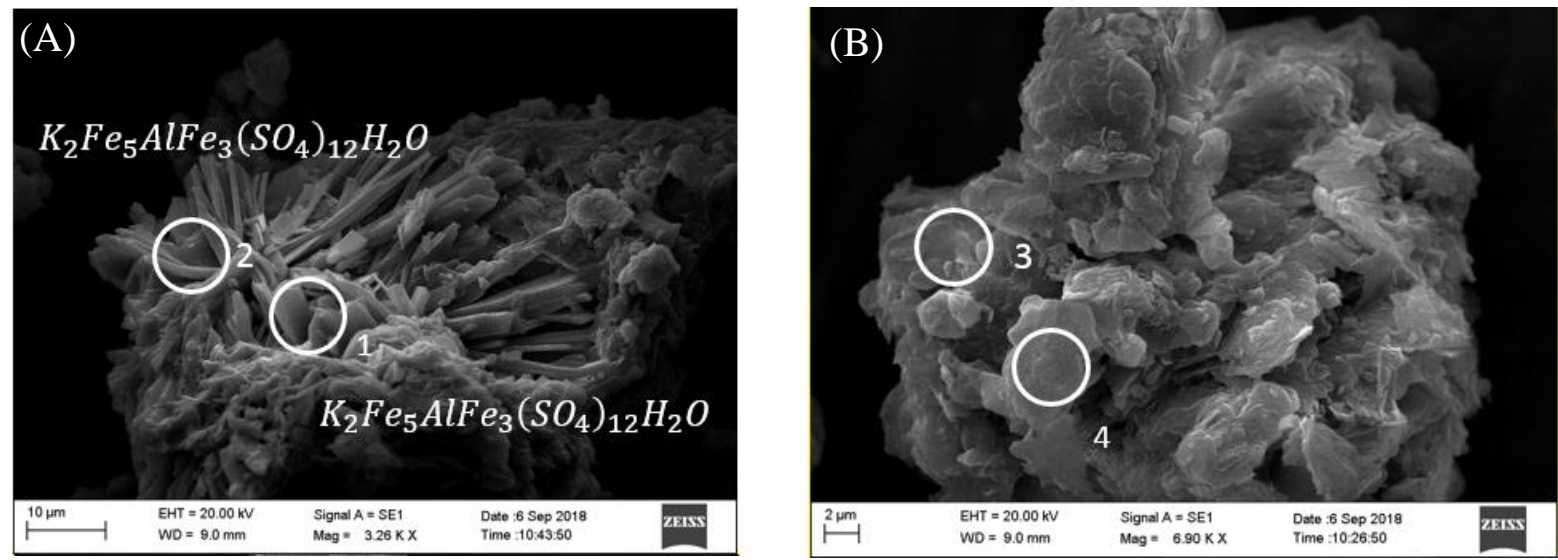

Tabela 3- Resultado do EDS da amostra da reação com duração de 15 minutos.

\begin{tabular}{|c|c|c|c|c|c|c|c|c|c|}
\hline \multicolumn{10}{|c|}{ Análise EDS (\% em peso) } \\
\hline Ponto & & & & & Element & & & & \\
\hline & $\mathrm{C}$ & $\mathrm{O}$ & $\mathrm{Mg}$ & $\mathrm{Al}$ & $\mathrm{Si}$ & $S$ & $\mathrm{~K}$ & $\mathrm{Fe}$ & $\mathrm{Au}^{*}$ \\
\hline 1 & 3.45 & 46.88 & 0.40 & 0.93 & 0.87 & 17.96 & 8.77 & 10.35 & 8.20 \\
\hline 2 & 11.62 & 33.07 & 0.55 & 1.11 & 1.83 & 16.39 & 8.28 & 10.87 & 14.25 \\
\hline 3 & & 47.49 & 0.65 & 8.45 & 19.27 & 3.76 & 5.45 & 0.21 & 0.74 \\
\hline 4 & 2.12 & 51.32 & 0.45 & 3.99 & 26.15 & & 2.07 & 0.60 & 13.18 \\
\hline
\end{tabular}

Os teores obtidos pela análise EDS, apresentados na Tabela 3, ratificam os resultados adquiridos por meio do DRX (Figura 3 (B)), uma vez que nos pontos 1 e 2 os elementos encontrados são os necessários para formação do sulfato $\mathrm{K}_{2} \mathrm{Fe}_{5} \mathrm{AlFe}{ }_{3}\left(\mathrm{SO}_{4}\right)_{12} \mathrm{H}_{2} \mathrm{O}$, e os pontos 3 e 4 tem-se possivelmente a presença do verdete in natura que não reagiu.

\section{CONCLUSÃO}

Culmina-se que o ácido sulfúrico é eficaz no aumento da solubilidade do potássio no siltito verde, chegando a extrair em 5 minutos de reação com RLS 2,11 quase $10 \%$ de solubilização do K total do minério. Quando aumenta-se a RLS para 10 e faz-se a extração por água, tem-se resultados mais expressivos, a extração do potássio chega a $18 \%$ do potássio total, porém foi necessário um maior tempo de reação.

Conclui-se também, que na maior RLS analisada existe um pico em 5 horas de reação e que na menor RLS, existem picos de solubilização em 5, 15 e 60 minutos de reação e após as análises de DRX, MEV e EDS nos produtos, conclui-se que possivelmente há a formação do sulfato $\mathrm{K}_{2} \mathrm{Fe}_{5} \mathrm{AlFe}_{3}\left(\mathrm{SO}_{4}\right)_{12} \mathrm{H}_{2} \mathrm{O}$, e que ainda existe verdete in natura não reagido em todos os produtos dos diferentes tempos de reação, já que os resultados das análises convergem. 


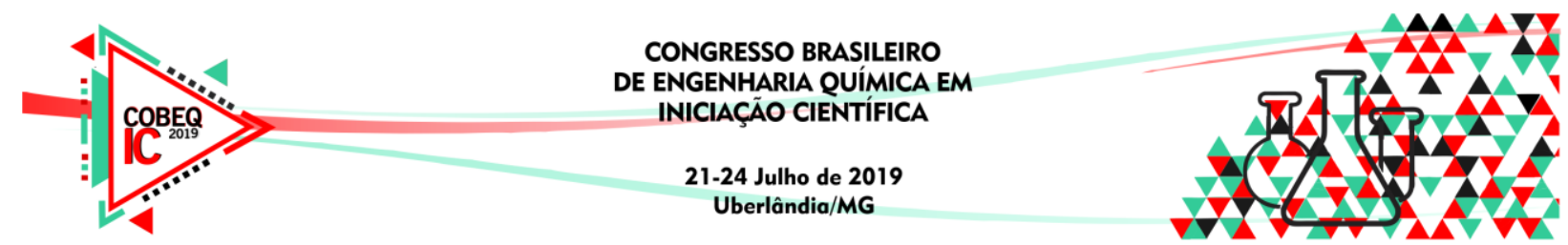

\section{REFERÊNCIAS}

LOPES, A. S.; GUILHERME, L. R. G. Fertilidade do solo e produtividade agrícola. In: NOVAIS, R. F.; et al. (Ed.). Fertilidade do solo. Viçosa: Sociedade Brasileira de Ciência do solo, 2007.

McKinsey \& Company. Resource Revolution: Meeting the world's energy, materials, food, and water needs. Nov, 2011

MOREIRA, S. D; UHLEIN, A; FERNANDES, S. L. M; MIZUSAKI, M. A; GALÉRY, R; DELBEM, D. I. Estratigrafia, petrografia e mineralização de potássio em siltitos verdes do grupo Bambuí na região de São Gotardo, Minas Gerais. Geociências, São Paulo v. 35 n. 2, p.157-171, 2016.

NASCIMENTO, L. R; MIRANDA, A. L. Exploração de potássio no Brasil. Brasília: Consultoria Legislativa da Câmara dos Deputados, 2015.

NASCIMENTO, M. LOUREIRO, F.E.L. Fertilizantes e sustentabilidade: o potássio na a agricultura brasileira, fontes e rotas alternativas. Rio de Janeiro: CETEM/MCT, 66p. (Série Estudos e Documentos, 61), 2004.

SILVA, A.A.S.; MEDEIROS, M.B.; SAMPAIO, J.A.; GAMIDO, F.M.S. Verdete de cedro de Abaeté como fonte de potássio: caracterização, tratamento térmico e reação com $\mathrm{CaO}$. Revista Matéria, 17:1062-1073, 2012a.

U.S.G. Survey, Mineral commodity summaries 2018: U.S. Geological Survey, 2018, p. 200.

WEED, S. B.; DAVEY, C. B.; COOK, M. G. Weathering of mica by fungi. Soil Science Society American Procedures, v. 33, p. 702-706, 1969. 